from the surface. The pressure was so great against the overlying strata that the water in rising blew a hole in the factory roof, and flowed at the rate of 100,000 gallons an hour. Water under similar pressure was found at Virginia Water, where it rose $90 \mathrm{ft}$. above the ground. Instances were given where the flow of water was in the first place very great, but owing to the silting-up of the bore-holes with fine sand and clay the supply rapidly fell off.

Prof. E. B. Poulton gave a lecture on "The Power of Changing Colour as a Form of Protective Resemblance", and an address was given by Sir Lawrence Chubb to the Regional Survey Section on "The Rights of Way Act, 1932".

The excursions were of considerable value. Silchester was visited, and the Botanical Section explored Greenham Common and the Kennet Valley.
The valuable farms of the University at Shinfield, Sutton's Seed Trial Grounds, and Huntley and Palmer's factory were also visited. Prof. Hawkins led the geologists to Kingsclere, and to Theale and Pangbourne, in the latter showing how the Kennet water is to a great extent conveyed by underground channels to the Sulham stream and so to the Thames at Pangbourne, instead of following the main Kennet River to Reading, whilst the Pang itself is now almost dry. The final excursion was a long one to the Vale of White Horse, passing on the way the dolmen known as Wayland Smith's Forge, and Uffington camp, afterward reaching Uffington by way of the neck and body of the so-called White Horse, which, however, may be the hen-headed dragon of the Celts, said to have been slain by St. George on the flat-topped hill isolated below.

\title{
A Quantitative Study of Trance Personalities
}

T $T$ is well known that the Society for Psychical 1 Research has for many years studied the variations of personality observed in the mediumistic trance. This has generally been done by means of historico-legal methods, that is, by estimating the evidential value of the statements made by the personalities alleged to be communicating through the medium under observation. This procedure is a perfectly valid one, and it would be entitled to full experimental status if a more reliable method than any used hitherto of computing the value of such free material could be devised. Nevertheless, it is obviously desirable that these trance personalities should be investigated by normal quantitative methods, and to this problem the Society for Psychical Research has now turned its attention.

Mr. Whately Carington (formerly Whately Smith) has attempted to apply to trance personalities the well-known technique of the word association test and the psychogalvanic reflex. A list of words is read out to the subject, who is supposed to react to each stimulus word with the first word that enters his consciousness; his response is recorded, together with the time taken by him in answering and the change in the electrical resistance of the subject's skin resulting from the 'excitement' produced in him by the stimulus word. There is good experimental reason for believing that the magnitude of this change (measured with a Wheatstone bridge and galvanometer) is a fair measure of such excitement. When the standard list of 100 words has been gone through in this way, it is rapidly read over a second time to test the subject's accuracy in reproducing his responses, failure to do so being regarded as an indication that an inhibitory complex is present. The whole process is gone through several (usually six) times to obtain a reliable mean, and the resulting data are regarded as characteristic of the subject's personality.

Such is the technique in general, on which Mr. Carington is an acknowledged authority, and which he has now attempted to apply to the problems of psychical research. If tests were to be applied to a medium in his normal state and then to a trance personality manifesting through the same medium's body, with his normal consciousness in abeyance, a comparison of the two series of data would clearly yield information as to the degree of likeness or unlikeness between the two personalities. Thus, Mr. Carington argues, definite evidence would be obtained regarding the status of the trance personality.

In his present report (Proc. Soc. Psych. Res., 42, 173-240, July 1934) Mr. Carington sets out the results of a first experiment on these lines, carried out with the mediums Mrs. Garrett, Rudi Schneider and Mrs. Leonard. Unfortunately, in each of these cases the circumstances were such that a full investigation was impossible. Mrs. Garrett turned out to be a very difficult subject for psychogalvanic reflexes, the electrical resistance of her skin being erratic to such a degree that the resulting material was inadequate for the application of Prof. R. A. Fisher's analysis of variance. In the case of Rudi Schneider, the subject did not fully co-operate, so that the results cannot be taken at their face value. In the case of Mrs. Leonard it was not possible to test the psychogalvanic reflex at all, tho experiment being limited to reaction times and the reproduction test. From the fragmentary data obtained with these subjects, Mr. Carington concludes that in the case of Mrs. Garrett she and her 'control' Uvani are significantly different; that Schneider and his 'control' Olga are significantly similar; and that in the case of Mrs. Leonard, her 'control' Feda, and two other of her trance personalities, significant differences exist.

It will be asked of what these differences are held to be significant. On this point $\mathrm{Mr}$. Carington ex. presses himself with due caution, but it is clearly his opinion that if Mrs. Garrett's and Mrs. Leonard's 'controls' were merely split-off secondary personalities, they would not have shown the differences they actually yielded. Unreserved acceptance of this conclusion would, however, be premature, for next to no information is available as to the amount of similarity or difference these tests would yield if actually applied to a pathological case of secondary personality, to a subject in hypnosis, or even to an actor playing a part. Moreover, the results seem far too dependent on the goodwill and free co-operation of the subject. Mr. Carington has undoubtedly made a valuable and thoroughly scientific contribution to psychical research, of a kind warmly to be welcomed, but a series of control experiments is essential before his results justify any generalisation with paranormal implications. 